\title{
Assessment of triage accuracy by Nurses, and delay care of acute myocardial infarction patients admitted to Emergency Department: retrospective analysis from Shifa International Hospital, Pakistan
}

\author{
Kiran Shabbir ${ }^{1}$, Waqar Javeed ${ }^{1}$, Abeer Kazmi ${ }^{2}{ }^{*}$, Muhammad Adnan Shereen $^{3}$, Nadia Bashir ${ }^{3}$
}

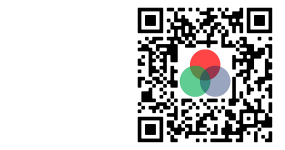

Use your smartphone to scan this QR code and download this article

\begin{abstract}
Background: Coronary vascular disease (CVD) is the premier cause of fatality in the world. In Pakistan, 30 to 40\% of all deaths occur due to CVD. The emergency department triage is carried out to prioritize the care of critical patients. Errors during triage may lead to mortality and morbidity of the patient. The current study's objective is to determine the triage process of acute myocardial infarction patients and its associated accuracy and delays during the acute myocardial infarction process of care in the emergency department. Methods: In this descriptive study, data were collected retrospectively from Shifa International Hospital. The consent was taken from participating Registered nurses (RNs) who were involved in the triage process. Nurses with experience of less than 1 year in the emergency department were not part of the study, while only those patients with symptoms indicative of Acute Myocardial Infarction and age of 21 years or older were included in the current study. EMR system was used on a daily basis as a method to capture data for the study. The actual clock time in minutes from arrival until triage and obtain ECG as greater than 10 minutes was identified as a delay. Results: The 8 R.N. participated in the current study with a mean age and experience of 28.11 years and 4.77 years. The patients' age was $22-74$ years, which consist of $58.9 \%$ male and $41.1 \%$ female. Out of 224 patients, $20.53 \%$ of patients were smokers, $39.3 \%$ were diabetic, $44.6 \%$ were CVD, and $78.5 \%$ were reported for chest pain. Delay care such as the mean triage and ECG time recorded was 6.75, and $7.30 \mathrm{~min}$, the mean E.R. physician and Cardiology resident assessment was $11 \mathrm{~min}$ and 25.19 min, respectively, which were significantly found according to the recommended guidelines of AHA. The triage accuracy in the current study was recorded as $80.35 \%$. Conclusion: In Pakistan, no proper triage system is developed, and no time limits and guidelines are defined for the completion of the triage process. In the current study, the triage level designations, ECG delay, E.R. and cardiology resident assessment delay were found insignificant, and triage designation was found inaccurate with $19.6 \%$ of patients, which lead to delay the re-perfusion therapy. In patients with AMI symptoms, triage accuracy and quick ECG helps E.R. physician assessment to take a quick better decision for cardiac care. It helps patients to get re-perfusion therapy on time for acute myocardial infarction.
\end{abstract}

Key words: Acute myocardial infarction patients, Triage accuracy, ECG, American Heart Association (AHA)

Abeer Kazmi, Department of Biotechnology, Faculty of Chemical and Life Sciences, Abdul Wali Khan University, Mardan, Pakistan

Email: Abeer_Kazmi@yahoo.com

\section{History}

- Received: 2020-10-31

- Accepted: 2021-01-15

- Published: 2021-02-09

DOI : 10.15419/ajhs.v7i1.480

\section{Check for updates}

\section{Copyright}

(C) Biomedpress. This is an openaccess article distributed under the terms of the Creative Commons Attribution 4.0 International license.

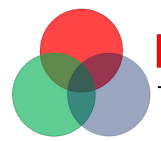

\section{INTRODUCTION}

In Pakistan's population, coronary vascular diseases become the premier risk; due to this disease, 30-40\% of all deaths occur in Pakistan. Every year the death caused by cardiac disease is extended to 200,000 per year $^{1,2}$. Annually, more than 7.6 million patients were admitted to Emergency Departments in the U.S., with chest pain's main complaint ${ }^{3}$. It was reported that $31 \%$ of all deaths occur due to cardiovascular disease, with $80 \%$ happening in low- and middle-income countries ${ }^{4}$. In the Emergency Department, the accurate and timely triage level designation plays a key role in lessening death and disease. Still, facts show that accuracy rates are low, which delays the care process of a patient. In the American Heart Association (AHA) national guidelines, it is mentioned that health care providers need to fulfill cardiac emergency care goals from point of entry in emergency department to 90 minutes ${ }^{5}$. In acute myocardial infarction, electrocardiograms obtain, and doctors are evaluated within 10 minutes, and start thrombolytic medications within a half hour (labeled as door-to-needle or fibrinolysis) or provide percutaneous coronary intervention (labeled as door-to-balloon) within one and half hour ${ }^{6}$. To restore blood flow in the heart, rapid 
assessment and treatment are vital for the heart to preserve cardiac function. First of all, the nursing triage is done in the emergency department, which directly affects initial interventions and care as their skills to identify the Acute Myocardial Infarction play a vital role in taking rapid action. After the first occlusion, the Cardiac cell death can happen within twenty minutes or up to two hours ${ }^{7,8}$.

The struggle to handle most patients coming for healthcare is done by the Management of Emergency, physician, and R.N.s ${ }^{9}$. The Emergency Triage Nurse's main role is to define the severity of disease and urgency of care required, such as in cardiac emergency patients, who require rapid care in triage. However, triage requires certain diagnostic tests to aid decisions. The subjective decision of triage level designation depends upon the collected data, observations, brief assessment of nursing, medical history, patient symptoms, and occasionally family history ${ }^{10,11}$. In Pakistan, no proper triage system is developed, and no time limits and guidelines are defined for the completion of the triage process. The patient's assessment and a triage level designation is the triage goal representing symptoms urgency ${ }^{12}$. The Emergency Department can use ESI tool for accurate triage level to aid early interventions and affect patient outcomes. In Pakistan, the Triage system was introduced a few years ago in some hospitals. The triage process's standard guidelines are not available in Pakistan however, few hospitals in Pakistan have implemented a three or five-level triage system ${ }^{13,14}$. This study will conclude the effectiveness of five-level ESI in a patient with acute myocardial infarction patient in the Emergency Department.

\section{METHODOLOGY}

\section{Research Design}

This was a cross-sectional study in which prospective data for R.N. triage process in the Emergency Department was utilized. The data was collected through R.N. of patients involved directly in the triage process to determine the delay in care and accuracy of the designation of R.N. triage level. The data was collected from patients with symptoms suggestive of acute myocardial infarction by using EMR system of E.D. department daily. Data was collected by using hospital medical record file of patients such as the (a) characteristics of patients (age, race/ethnicity, gender, past medical history and presentation of symptom), characteristics of R.N. (age, level of education, years of experience in Nursing and Emergency department), and (b) delay in ECG obtainment, E.R. physician assessment, cardiology resident assessment and designation of triage level accuracy given by R.N. in the triage of Emergency Department. The study dependent variables were the designation of triage level accuracy, time to initial triage assessment, time to gain an Electrocardiogram, time to E.R. physician assessment, and time to cardiology resident.

In this research study, the patients admitted to the emergency department with a complaint of pain in the chest, indicative symptoms of acute myocardial infarction were included to produce the required data required. Shifa International Hospital, located in Islamabad, Pakistan, with more than 400 beds, was the designated site to conduct the study. With one year in nursing, the nurses who understand the ESI triage process and are involved in the current study were included in the triage process.

To select a sample from the population for study, the inclusion criteria were patients presenting with symptoms indicative of Acute Myocardial Infarction. The age of the patient must be 21 years old and older. Data were collected for two months of the patient who were presented in the emergency department of tertiary care hospital.

\section{Data collections}

The EMR system was used daily as a method to capture data for the study. The patient files were retrieved by requesting to the medical record department. The collected data was reviewed to fill data collecting form as well as patient demographics. A patient EMR sample was utilized by following inclusion and exclusion criteria to get Emergency Department variables related to triage. The presenting complaints were chest discomfort or chest pain, diaphoresis, nausea, palpitation, shortness of breath, syncope, vomiting, or weakness suggestive of Acute Myocardial Infarction symptoms. The actual clock time from arrival to triage and ECG results are then identified as a delay if greater than 10 minutes. The additional likely points or delay was arrival time for evaluation of E.R. physician greater than $10 \mathrm{~min}$, and cardiology resident arrival time for assessment greater than 30 min was also collected.

\section{Triage process}

The designation of triage level 2 must have been given to patients presenting with symptoms indicative of acute myocardial infarction (AMI). The designation of the level of triage was coded as inaccurate for this study if it was not given. The dichotomously dependent variables were coded as yes for accurate and no for inaccurate. 


\section{Analysis of Data}

The frequencies of the categorical variables were calculated through Descriptive statistics. The continuous variables descriptive were calculated to conclude that (1) if values are missing, and (2) the data distribution. The Statistical Package for the Social Sciences (SPSS; Version 22.0) software was utilized for all data analysis.

\section{RESULTS}

Table 1: Years of experience of Registered nurses in Emergency department

\begin{tabular}{lcc}
\hline $\begin{array}{l}\text { Years of RN Experience in } \\
\text { ED }\end{array}$ & Frequency & Percent \\
\hline less than 1 year & 1 & 12.5 \\
1 to 2 year & 3 & 37.5 \\
more than 2 year and 3 year & 1 & 12.5 \\
3 to 5 year & 2 & 25.0 \\
5 to 7 year & 1 & 12.5 \\
Total & 8 & 100.0 \\
\hline
\end{tabular}

There were 12 nurses recognized among 70 nurses working in the emergency department by following the inclusion criteria of the study. Only 8 R.N. were given consent to participate, contributed to a $67 \%$ response rate, consisting of 2 females and 6 males, as shown in Figure 1. The age range was $24-33$ years of nurses with a mean age was 28.11 years $(\mathrm{SD}= \pm 2.31$ ), and experience as R.N. was 2-7 years with mean 4.77 years $(\mathrm{SD}= \pm 1.20)$ in the Emergency department (Table 1). Most of the nurses had diplomas (75\%), while the remaining $25 \%$ hold a bachelor's degree in nursing. Total 224 patients were detected with an age range of 22 - 74 years, which constitute $59 \%$ male and $41 \%$ female (Tables 2 and 3 ).

Table 2: Age of acute myocardial infarction patients admitted to Emergency Department

\begin{tabular}{lcc}
\hline Age in years & Frequency & Percent \\
21 - 30 year & 26 & 11.6 \\
31 - 40 year & 30 & 13.4 \\
46 - 60 year & 78 & 33.9 \\
61 - 70 years & 58 & 25.9 \\
71 and above years & 34 & 15.2 \\
Total & $\mathbf{2 2 4}$ & $\mathbf{1 0 0 . 0}$ \\
\hline
\end{tabular}

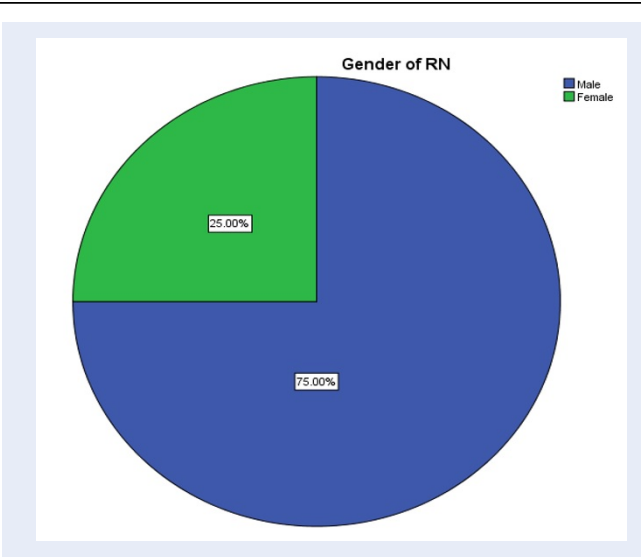

Figure 1: Gender and percentage of Registered nurses working in emergency department for triage of acute myocardial infarction patients

Table 3: Demographic analysis of acute myocardial infarction patients admitted to Emergency Department

\begin{tabular}{lcc}
\hline Variable & Frequency & Percentage \\
Gender & 132 & 58.9 \\
Male & 92 & 41.1 \\
Female & & \\
Marital Status & 06 & 2.68 \\
Single & 218 & 97.32 \\
Married & & \\
Race/ethnicity & 220 & 98.2 \\
Asian & 04 & 1.8 \\
\hline Non-Asian & & \\
\hline
\end{tabular}

Note $\mathrm{n}=224$

Among all patients, 46 (20.5\%) patients were smokers, 88 (39.3\%) were diabetic and 100 (44.6\%) were reported about their cardiac disease history. 166 patients (78.5\%) stated clearly about chest pain at triage, along with their other symptoms (Table 4).

The triage level 2 should have been designated to a cardiac patient who has severe chest pain and suspicion of acute myocardial infarction. With 180 frequency of patients, $80.35 \%$ overall accuracy rate of triage is recorded.

The Delay care was demarcated as the number of minutes a patient waited to be triaged by R.N., number of minutes a patient waited to have an ECG performed, number of minutes' a patient waited to be seen by an E.R. physician, and the number of minutes a patient waited to seen by a cardiologist. Those time points are 
Table 4: Co-disease and characteristics acute myocardial infarction patients admitted to

Emergency DepartmentTriage Level Designation by Priority Nurse to acute myocardial infarction patients

\begin{tabular}{lcc}
\hline Variable & Frequency & Percentage \\
Smoker & 46 & 20.5 \\
Yes & 178 & 79.5 \\
No & & \\
Diabetes Mellitus & 88 & 39.3 \\
Yes & 136 & 60.7 \\
No & & \\
Previous cardiac disease & 100 & 44.6 \\
Yes & 124 & 55.4 \\
No & & \\
Chest pain in triage & 166 & 78.5 \\
Yes & 48 & 21.5 \\
\hline No & & \\
\hline Noten
\end{tabular}

Note $\mathrm{n}=224$

Table 5: Triage Level Designation by Priority Nurse to acute myocardial infarction patients

\begin{tabular}{lcc}
\hline Triage Level Designation & Frequency & Percent \\
Accurate & 180 & 80.35 \\
Inaccurate & 40 & 19.65 \\
Total & 224 & 100.0 \\
\hline
\end{tabular}

Table 6: Time recorded (in minutes) for Delay care of acute myocardial infarction patients

\begin{tabular}{lccc}
\hline Variable & Mean & Range & SD \\
Minutes to triage & 6.75 & $1-13$ & \pm \\
& & & 2.72 \\
& & & \\
Minute to ECG time & 7.30 & $1-16$ & \pm \\
& & & 3.07 \\
& & & \\
$\begin{array}{l}\text { Minutes ER physician assess- } \\
\text { ment time }\end{array}$ & 11.00 & 13 & \pm \\
& & & 2.76 \\
$\begin{array}{l}\text { Minute to Cardiology resident } \\
\text { assessment time }\end{array}$ & 25.19 & 44 & \pm \\
\hline
\end{tabular}

identified in Table 6. It is noteworthy that the meantime to triage was recorded 6.75 minutes, the meantime to ECG was 7.30 minutes, the meantime to E.R. physician assessment was 11 minutes, and the meantime to cardiology physician checkup was $25.19 \mathrm{~min}$ utes. The recorded time in the current study is significantly inside the recommended guidelines of AHA for cardiac patients.

\section{DISCUSSION}

In this study, a total 224 patients were included, 166 (78.5\%) of acute myocardial infarction had got triage level 2 designation, which was appropriate. This triage level designation is important in defining how rapidly the patient gets an ECG and is assessed by a healthcare physician. Thus, an accuracy rate of $80 \%$ was acceptable but still concerning in terms of patient life. The priority nurse probably had trouble defining the symptoms which characterized ACS. According to Previous studies, the triage accuracy rate was $50 \%$ to $76 \%{ }^{15-17}$.

This study contains several limitations as it does not explore all the factors, cause and effect of relationship and association among variables which affect the triage decision. Yet, this variation in nurse triage decisions might be due to other circumstance which was not explored, such as priority nurse critical thinking skills, E.D. infrastructure, and decision-making functions. In this study, variables were recognized that might describe accuracy in triage level designations. The patient and R.N. variables were recognized as significant in determining the accuracy of triage designation.

In this study, patients' pictorial description of pain for R.N.s was renowned as an important decision point. Though the accuracy rate was only $80 \%$, a significant relationship was observed between accuracy and chest pain patient reports. Those patients reporting chest pain were more expected to be triaged accurately. It was expected that more patients would present with atypical symptoms and not report chest pain, but only $(\mathrm{N}=48) 21.5 \%$ reported no chest pain along with other symptoms such as shortness of breath, syncope, palpitations, apprehension, and diaphoresis. In this study, $78.5 \%$ reported chest pain in the initial triage documentation. It might be due to the priority nurse question about chest pain; they might give a positive response by considering it a true emergency. As cardiac ischemia main symptom was Chest pain. Therefore, these patients were triaged accurately, which was $80 \%$, and got a level 2 designation, resulting in better triage accuracy in chest pain 
patients. According to previous reports, the BSN education level has been identified as positively affecting general patient results because the nursing purpose is triage-level designation decisions, which might lead to bad patient consequences ${ }^{12,18}$. BSN rather than R.N triaged almost $50 \%$ of the patients.

The overall delay occurs in the Emergency Department for acute myocardial infarction patients. However, rapid identification is vital for the initiation of reperfusion therapy in acute myocardial infarction ${ }^{19,20}$. The cardiac patient waited, proceeding by priority to initiate the triage assessment, a mean of 6.75 minutes (range 0-13 minutes). Many studies have recognized overall E.D. wait times that are prolonged and fall outside the ESI level recommendations for the right care and better results. In previous studies, the mean delay triage time recorded was 27 $\mathrm{min}, 26 \mathrm{~min}$, and $14 \mathrm{~min}$, regardless of the severity of chief complaint ${ }^{17,21,22}$. In the current study, 6.75 min triage meantime, $7.30 \mathrm{~min}$ ECG meantime, 11 min E.R. physician assessment meantime, and 25.19 min cardiology resident assessment meantime was recorded. It might be due to better emergency department infrastructure, due to good clinical knowledge and experience of priority nurse and the quality implementation of triage system by E.D. management to get a better outcome in acute myocardial infarction patients.

\section{CONCLUSION}

In this study, the triage level designation accuracy rate and delay care in acute myocardial infarction patients were identified. Triage level designation, ECG delay, E.R. physician assessment delay, and cardiology resident assessment delay were insignificant. Still, triage designation was not accurate in $20 \%$ of the patient might lead to a bad outcome in these cardiac patients. Patients who reported chest pain were predictive of better accuracy and did not delay ECG, E.R. physician assessment, and cardiology resident assessment. In patients with acute myocardial infarction symptoms, delays in triage level designation may result in a significant delay in emergent cardiac care.

Similarly, delay in ECG led to a prolonged delay in emergent cardiac care. On the other hand, E.R. physician assessment delays lead to a delay in emergency care. Similarly, the cardiology resident delay assessment delayed getting re-perfusion therapy by acute myocardial infarction, which leads to bad outcomes. This study contains several limitations as it does not explore all the factors, cause and effect of relationship and association among variables which affect the triage decision. Yet, this variation in nurse triage decisions might be due to other circumstance which was not explored, such as priority nurse critical thinking skills, E.D. infrastructure, and decision-making functions. So, it is recommended to evaluate other factors affecting triage level designations decisions and determine the relationship among variables.

\section{COMPETING INTERESTS}

The authors declare that they have no competing interests.

\section{REFERENCES}

1. Nazar M, et al. Effectiveness of health literacy intervention on cardiovascular diseases among university students of Pakistan. BMC health services research. 2019;19:504. PMID: 31324165. Available from: https://doi.org/10.1186/s12913019-4348-y.

2. Tanvir S, Sajjad S, Roshan R. Awareness levels of prevention of cardiac diseases in general population of rawalpindi and requirement of health education. Public health. 2018;157:107110. PMID: 29505914. Available from: https://doi.org/10.1016/ j.puhe.2018.01.006.

3. Roth GA, Johnson CO, et al. The burden of cardiovascular diseases among U.S. states 1990-2016. JAMA cardiology. 2018;3:375-389.

4. Katan M, Luft A. Global burden of stroke. Paper presented at: Seminars in neurology (Georg Thieme Verlag). 2018;PMID: 29791947. Available from: https://doi.org/10.1055/s-00381649503.

5. Lin YK, et al. Comparison between simple triage and rapid treatment and Taiwan Triage and Acuity Scale for the emergency department triage of victims following an earthquakerelated mass casualty incident: a retrospective cohort study. World journal of emergency surgery. 2020;15:1-8. PMID: 32156308. Available from: https://doi.org/10.1186/s13017020-00296-2.

6. Wolf LA, et al. Triaging the emergency department, not the patient: United States emergency nurses' experience of the triage process. Journal of emergency nursing. 2018;44:258266. PMID: 28750891. Available from: https://doi.org/10.1016/ j.jen.2017.06.010.

7. Chang AM, Cohen DJ, et al. Hospital strategies for reducing emergency department crowding: a mixed-methods study. Annals of emergency medicine. 2018;71:497-505. PMID: 28844764. Available from: https://doi.org/10.1016/j. annemergmed.2017.07.022.

8. Nevill A. The influence of nurse allocated triage category on the care of patients with sepsis in the emergency department: A retrospective review. Australasian Emergency Care. 2020;PMID: 33012700. Available from: https://doi.org/ 10.1016/j.auec.2020.09.002.

9. Hardavella G, Aamli-Gaagnat A, et al. Top tips to deal with challenging situations: doctor-patient interactions. Breathe. 2017;13:129-135. PMID: 28620434. Available from: https: //doi.org/10.1183/20734735.006616.

10. Noon AJ. The cognitive processes underpinning clinical decision in triage assessment: A theoretical conundrum? International Emergency Nursing. 2014;22:40-46. PMID: 23685041. Available from: https://doi.org/10.1016/j.ienj.2013.01.003.

11. Sammons SS. Accuracy of Emergency Department nurse triage level designation and delay in care of patients with symptoms suggestive of acute myocardial infarction. 2012;.

12. Sanders SF, DeVon HA. Accuracy in E.D. triage for symptoms of acute myocardial infarction. Journal of emergency nursing. 2016;42:331-337. PMID: 26953510. Available from: https:// doi.org/10.1016/j.jen.2015.12.011. 
13. Hyder AA, et al. One hundred injured patients a day: multicenter emergency room surveillance of trauma in Pakistan. Public health. 2017;148:88-95. PMID: 28431334. Available from: https://doi.org/10.1016/j.puhe.2017.03.006.

14. Khursheed M, Fayyaz J, Jamil A. Setting up triage services in the emergency department: experience from a tertiary care institute of Pakistan. A journey toward excellence. Journal of Ayub Medical College Abbottabad. 2015;27:737-740.

15. Arslanian-Engoren C, Eagle KA, Hagerty B, Reits S. Emergency department triage nurses' self-reported adherence with American College of Cardiology/American Heart Association myocardial infarction guidelines. Journal of Cardiovascular Nursing. 2011;26:408-413. PMID: 21263336. Available from: https://doi.org/10.1097/JCN.0b013e3182076a98.

16. Atzema $\mathrm{CL}$, et al. E.D. triage of patients with acute myocardial infarction: predictors of low acuity triage. The American journal of emergency medicine. 2010;28:694-702. PMID: 20637385. Available from: https://doi.org/10.1016/j.ajem.2009. 03.010 .

17. Wilper AP, et al. Waits To See An Emergency Department Physician: U.S. Trends And Predictors, 1997-2004: Overcrowding by patients unable to obtain nonurgent care elsewhere might be worsening care for those with truly urgent conditions. Health Affairs. 2008;27:w84-w95. PMID: 18198184. Available from: https://doi.org/10.1377/hlthaff.27.2.w84.
18. Rankin JA, Then $\mathrm{KL}$, Atack $\mathrm{L}$. Can emergency nurses' triage skills be improved by online learning? Results of an experiment. Journal of emergency nursing. 2013;39:20-26. PMID 21906796. Available from: https://doi.org/10.1016/j.jen.2011. 07.004 .

19. George L, Ramamoorthy L, Satheesh S, Saya RP, Subrahmanyam $D$. Prehospital delay and time to reperfusion therapy in S.T. elevation myocardial infarction. Journal of emergencies, trauma, and shock. 2017;10:64. PMID: 28367010. Available from: https://doi.org/10.4103/0974-2700.201580.

20. Rentrop KP, Feit F. Reperfusion therapy for acute myocardial infarction: Concepts and controversies from inception to acceptance. American Heart Journal. 2015;170:971-980. PMID 26542507. Available from: https://doi.org/10.1016/j.ahj.2015. 08.005 .

21. Hutchison AW, Malaiapan Y, Cameron JD, Meredith IT. Prehospital 12 lead ECG to triage S.T. elevation myocardial infarction and long term improvements in door to balloon times: The first 1000 patients from the MonAMI project. Heart, Lung and Circulation. 2013;22:910-916. PMID: 23994394. Available from: https://doi.org/10.1016/j.hlc.2013.07.014.

22. O'Donnell S, et al. In-hospital care pathway delays: gender and myocardial infarction. Journal of Advanced Nursing. 2005;52:14-21. PMID: 16149976. Available from: https://doi. org/10.1111/j.1365-2648.2005.03559.x. 